\title{
GEOMETRICAL CHARACTERIZATION OF YUCATAN CHURCHES
}

\author{
Isis Perez, Graça Vasconcelos, Paulo Lourenço \\ ISISE Department of Civil Engineering, University of Minho, Guimarães, Portugal
}

Contacting author: isisrodriguezp@gmail.com

\begin{abstract}
This paper presents the methodology used in the geometrical characterization of Yucatan churches. The main was determined the geometrical features of the typical profile that represent with the best accuracy the churches with canon vault built in the south of Mexico. The methodology was structure in two campaigns (1) Preliminary studies and (2) Statistical studies on the database. As a result, it seems that the Yucatan's churches were built totally in an intuitive way and they don't have clear numerical relationships, nevertheless, considering that the geometry of the structures has to be known in details, since it is fundamental for the intervention projects and mathematical modelling; in this work is explain the statistical and comparative surveys carried out to achieve a geometrical model with sufficient accuracy to characterize the cannon vault churches of Yucatan. Additionally, a linear correlation between variables is proposed.
\end{abstract}

Keywords: canon vaults, masonry, structural shapes, typical profile.

\section{Introduction}

In this research studies of Yucatan churches from sixteenth to eighteenth centuries was carried out. The main was determined the geometrical features of the typical profile that represent with the best accuracy the churches built in the south of Mexico. This geometry is high relevant in the develop of the principal investigation focused in the strengthening of connections by this kind of structures and the consequent assess of structural behaviour by the selected geometric model.

The relevance of this research is supported by the historical relevance that theses constructions represent.

In 1492 the first Spain people arrived in America developed a process of occupation by all wellknown. So, at the beginning of the 16th century, with the Spain people arrived the Franciscan religious who start the evangelization process to Catholicism. The evangelization process was supported by the massive construction of churches everywhere they arrived.

In 1537, they arrived in Yucatan Mexico and started the religious constructions for everywhere. Since Yucatan was a Maya region; in order to get control over the Mayan native, churches were built over the most important Mayan constructions, being nowadays the historical architectural legacy that is essential to conserve.

The clear description of analysis carried out in order to build all these constructions are not available. In Europe were used Agreements[1]-[3] that bring proportions or graphical rules to develop the churches geometry generally in span function. In Mexico there are not records that show the uses of these agreements[4]. The unknowledge by constructive rules and techniques difficult their understanding, preservation and rescue.

Considering that the geometry of the structure has to be known in details, since it is the base for 
the projects of intervention and for the mathematical modelling in the studies of conservation; in this work is explain the statistical and comparative surveys carried out to determine a geometrical model with sufficient accuracy used to characterize the cannon vault churches of Yucatan, México. It is considered that the knowledge created within this work can be applied in buildings worldwide with similar characteristics.

\section{Methodology}

The methodology was an exhaustive process because the selection of the most representative geometrical configuration was imminent to achieve the principal research, regarding to strengthening connections. This methodology was developed in two big steps that inside have many tasks.

- Preliminary studies. The Step 1 was collected all information available for the studies. Witch must include, historical study, architectural and materials survey, Geometrical rules described in historical manuscript, manuals or agreements and the identification of the principal variables.

- Statistical studies on the database. In the Step 2 was conduced all statistical analysis to determine the geometrical model. In this sense, two statistical approximations were carried out.

1. Firs Approximation. With the database collected in the Step 1, were performed the statistical analysis of the physical characteristics (e.g. kind of vault, constructive system of the vault, kind of masonry in walls and plant distribution) and geometrical characteristics (dimensions by each variable).

The physical characteristics were studied using bar diagrams. At the same time the geometrical characteristics were analysed using Statistical correlation between variables (i.e. simple regressions) and determined the most frequency values (i.e. histograms).

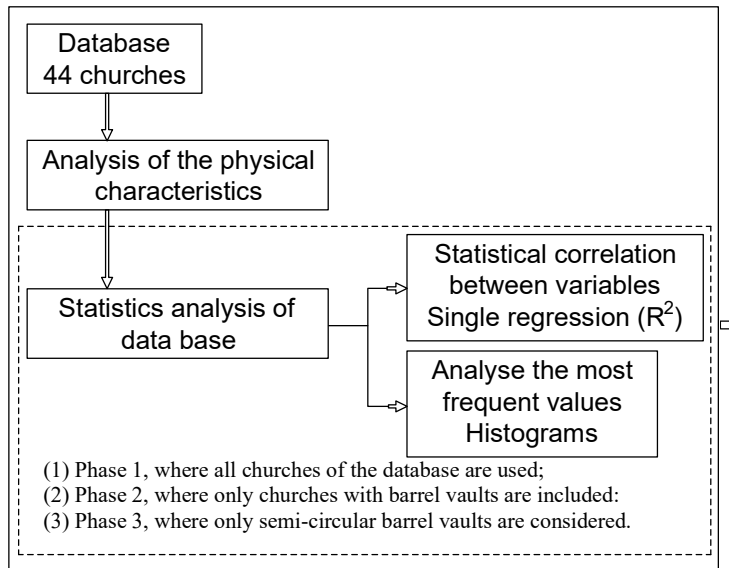

Figure 1. Statistical studies on the database. First Approximation methodology

Additionally, two discretization were conducted with the database and all statistical process was made again in each discretization.

2. Second approximation. The main in this review was define geometrical relations between the main variables and the span. The first task was to identify significant linear statistical correlations from each variable, this mean coefficient of variation $\left(R^{2}\right)$ greater than 0.6 . In addition, rations by parameters/span were analysed using histograms.

\section{Preliminary studies}

\subsubsection{Historical study}

The Franciscan occupation and the consequence built of churches were supported by the population density and the importance of the Mayan place. In the places with high population or high importance by Mayan people were built full churches with convents but in other places with lower population the churches were built by constructive stages. In these cases, first was build a 'visiting chapel' or 'open chapel' and through an evolution process in the time were finished the churches. [5] 


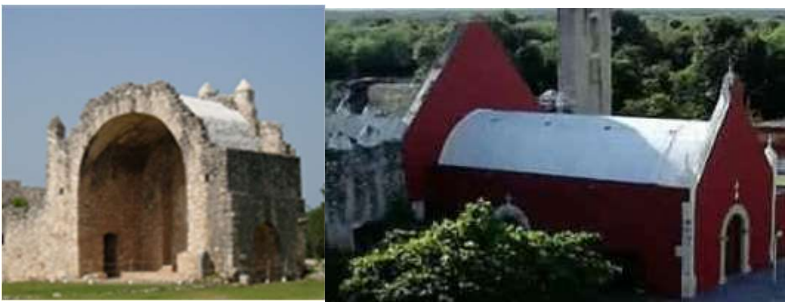

Figure 2. Open chapel and full church through an evolution process

\subsubsection{Review of Historical Manuals}

The main issue of this task was the analysis of the lineaments followed in the religious constructions of the sixteenth to the eighteenth century, because, as mentioned earlier, no agreements, manuals, records or evidences that support the analysis carried out for build all these constructions are available. So, European Geometrical rules described in historical manuscript, manuals and agreements were reviewed. The search was focus on churches with one span and barrel vault. It was considered that European rules could be used by Franciscans religious.

The vault thickness, probably the most important geometric parameter to determine, is provided by some authors based on unclear grounds and probably originating from experience; other as Fray Lorenzo do not say rule and indicates that the decision is of the builder.

In Figure 3 show the Empirical rules proposed by some authors regarding to vaults and walls dimensions.

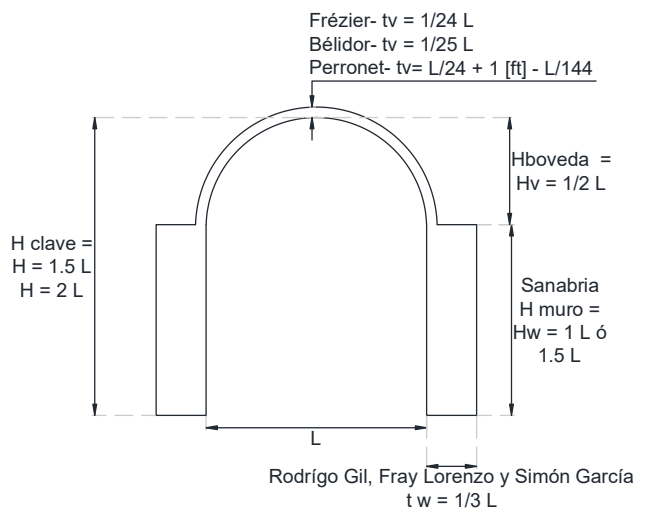

Figure 3. Empirical rules proposed in historical manuscript[1]-[3]

\subsubsection{Architectural survey}

In this task, the physical and geometrical features was recorded. A database of 44 churches was achieved. The database was composed of three sections, namely (1) General information; includes the location of the building, the identification number, name, and century construction; (2) Physical characteristics; included Kind of plant, material and typology by cross section of walls, typology and material of vaults and buttressed information; (3) Geometrical characteristics; record all dimensions relate to the main nave, walls and vaults as span, lengths, heights and thickness.

\subsubsection{Definition of the main variables}

The dimensions main to record were span (L), length (d), total height $(H)$, height of the wall $(H w)$, height of the vaults $(\mathrm{Hv})$, thickness of masonry walls (tw), thickness of vaults (tv) and wall extension over vault (Ew). The variables used are show in the Figure 4.

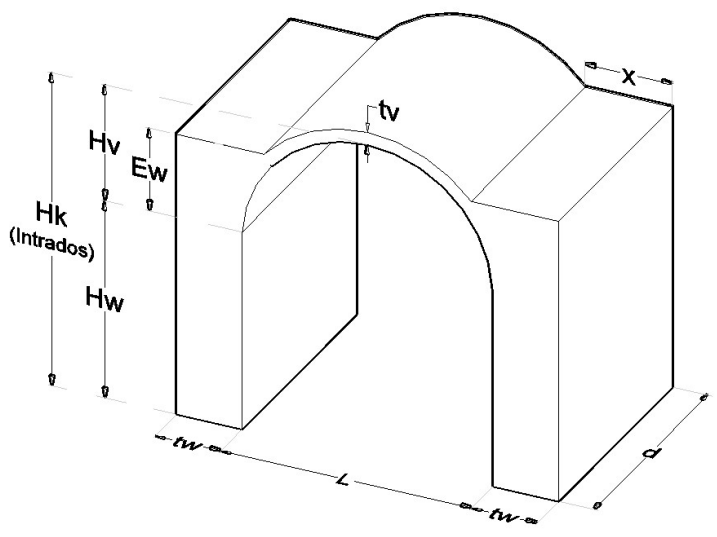

Figure 4. Description of key variables

\section{Statistical studies on the database}

\subsection{First approximation}

In this approximation, first task was analysed the physical features. This es relevant because define the physical characteristics to consider in a scale model reproduction or numerical analysis in future studies. The Bar diagrams were used in the analysis of kind of plant material and constructive system of vaults, material and constructive system of walls (e.g. Figure 5). 


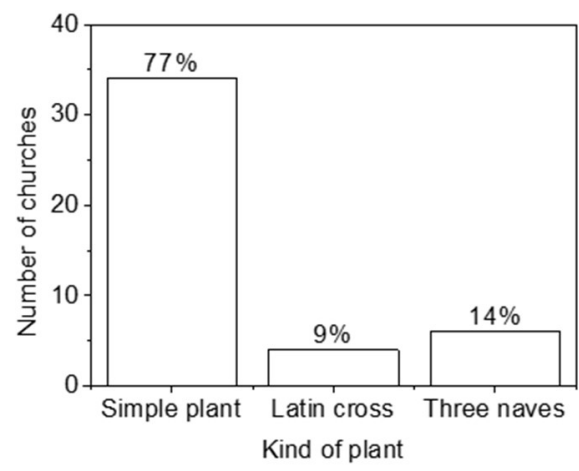

Figure 5. Typology of architectonical plant

Regarding to typology of Architectonical plant the result show that the $77 \%$ of churches have simple plant and the other $23 \%$ have typology. The wall analysis show that the $100 \%$ of churches have stone masonry walls with three leaves. The analysis of the vaults shows that the $74 \%$ are masonry vaults, $14 \%$ are vaults with wooden-logs with masonry and the last $12 \%$ are nowadays rebuilding or uncovered. Regarding the typology of vault the $59 \%$ are masonry canon vault, the $14 \%$ are wooden logs and masonry canon vaults, $11 \%$ are groin or sail vaults and the last $16 \%$ are rebuilding or uncovered.

The second task was conducted the statistical analysis of the database geometrical section. In this sense, for each variable described in Section 3.1.4, single regression through scatter diagrams and tendency lines with coefficient of variation $\left(R^{2}\right)$ were performed (e.g. Figure 6).
Additionally, analysis by the most frequent values through histogram were conducted (e.g. Figure 7). Valuable to note, this process was conducted for each approximation.

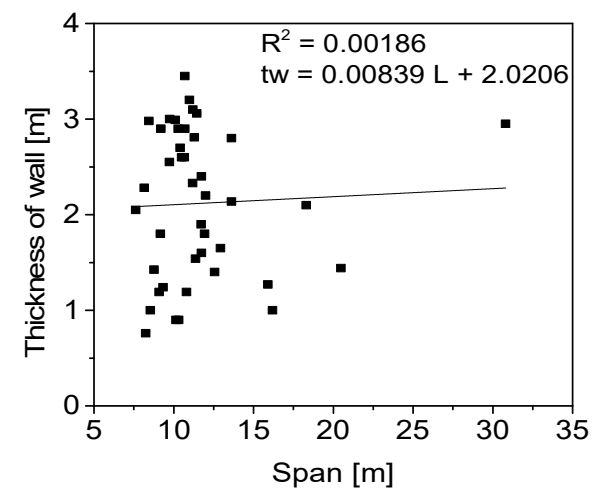

Figure 6. Statistical correlation between Span and Thickness of wall

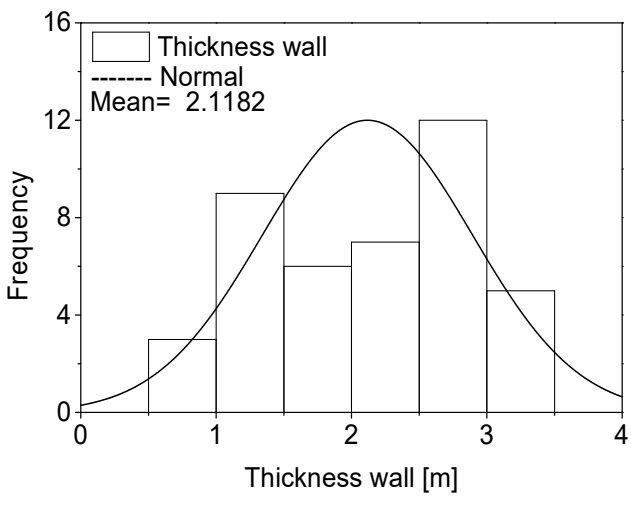

Figure 7. Histogram of Thickness wall

Table 1. Coefficient of variation $\left(R^{2}\right)$ obtained in each discretization.

\begin{tabular}{lcccccc}
\hline \multicolumn{1}{c}{ Variables } & $\begin{array}{c}\mathbf{R}^{\mathbf{2}} \\
\text { Phase 1 }\end{array}$ & $\begin{array}{c}\text { Data } \\
\text { number }\end{array}$ & $\begin{array}{c}\mathbf{R}^{\mathbf{2}} \\
\text { Phase 2 }\end{array}$ & $\begin{array}{c}\text { Data } \\
\text { number }\end{array}$ & $\begin{array}{c}\mathbf{R}^{\mathbf{2}} \\
\text { Phase 3 }\end{array}$ & $\begin{array}{c}\text { Data } \\
\text { number }\end{array}$ \\
\hline L vs Hv & 0.0780 & 33 & 0.2808 & 25 & $\mathbf{0 . 9 2 8 0}$ & 16 \\
\hline L vs Hw & 0.1905 & 39 & 0.0803 & 25 & 0.1868 & 16 \\
\hline L vs tv & 0.0125 & 13 & 0.2238 & 11 & 0.0396 & 7 \\
\hline L vs tw & 0.0018 & 42 & 0.0185 & 24 & 0.0055 & 16 \\
\hline L vs Hk & 0.3314 & 36 & 0.1583 & 26 & 0.4381 & 17 \\
\hline Hv vs tv & 0.2259 & 13 & 0.1001 & 11 & 0.0008 & 7 \\
\hline Hw vs tw & 0.0295 & 37 & 0.0135 & 23 & 0.0208 & 15 \\
\hline tw vs tv & 0.0005 & 23 & 0.0066 & 11 & 0.0868 & 7 \\
\hline Hw vs Hv & 0.0001 & 37 & 0.2571 & 25 & 0.2152 & 16 \\
\hline Hk vs Hw & 0.3443 & 37 & 0.5400 & 25 & 0.5063 & 16 \\
\hline- Desch & $\mathbf{0 . 6 4 3 3}$ & 37 & $\mathbf{0 . 9 1 6 2}$ & 25 & $\mathbf{0 . 9 0 7 3}$ & 16 \\
\hline
\end{tabular}

- Description of the variables in Error! Reference source not found. 
As was explain in the methodology the first approximation by geometrical characterization had three discretization by the database (1) Phase 1 , where all churches of the database are used; (2) Phase 2, where only churches with barrel vaults are included (3) Phase 3, where only semi-circular barrel vaults are considered. The result for each campaign is show in Table 1

In the Phase 1 (see Table 1), the coefficient of variation is small in all variables analyzed. One exception is the $\mathrm{Hk}$ vs $\mathrm{Hw}$ review that show a coefficient of variation greater than $0.60\left(R^{2}=\right.$ 0.6433). In the Phase 2 , the results were better than the first Phase. In this Phase, the vertical indoor dimension from the floor to key stone of the vault $(\mathrm{Hk})$ and the high of wall $(\mathrm{Hw}=$ vertical dimension from floor to start of the vault) show a lineal correlation of $R^{2}=0.91$. It means that $\mathrm{Hw}$ can be obtained with a reasonable accuracy through $\mathrm{Hk}$ using the expression $\mathrm{Hw}=0.7532 \mathrm{Hk}-$ 1.6543 .

Additionally, the variables $\mathrm{Hk}$ and $\mathrm{Hv}$ (high of the vault) have a correlation of $R^{2}=0.54$. Despite of this, these relations are not considered robust enough to generate a geometrical model that represents all churches of the database group because the rest of the coefficient of variation did not show good correlation.

In the Stage 3, the results continue to be discouraged, because only the correlation between the height of the key stone of the vault $(\mathrm{Hk})$ and the height of the wall $(\mathrm{Hw})$ was good $\left(R^{2}=0.9074\right)$. The relation $H k$ vs Hv results still in a coefficient of correlation lower than $0.6\left(R^{2}=\right.$
0.50). It is observed an increment in the coefficient of correlation with respect to Stage 2, but it is not considered to be significant.

The next task of this approximation was performances histograms by each variable. All of them were completed with a normal distribution diagram (Figure 7).

From these were selected the greater frequencies and average. This histogram process was repeat in each discretization. The Table 2 show the ranges selected.

As a result, geometrical proposals were made whit the frequencies minimum, maximum and the average. This last process was reproduced in each discretization and are show in Figure 8.

\subsection{Second approximation}

The aim of this approximation was to search Significant statistical correlations (i.e. the churches with similar geometrical characteristics). Linear correlations between geometrical parameters was work until the coefficient of variation by the Single regression shows a value of $0.6\left(R^{2}=0.6\right)$. See Figure 9.

The variables, coefficient of variation $\left(R^{2}\right)$, linear equations from this analysis are show in the Table 3. Also, the analyses of the most frequent rations: (parameters/span) were carried out using histograms as show the Figure 10. This was performed with the churches contained in the before regressions. All of histograms were completed with a normal distribution diagram.

Table 2. Selected frequency range for each phase.

\begin{tabular}{|c|c|c|c|c|c|c|c|c|c|}
\hline \multirow[b]{2}{*}{ Frequencies } & \multirow[b]{2}{*}{$\begin{array}{c}\text { Minimum } \\
\text { range } \\
\text { (m) }\end{array}$} & \multicolumn{2}{|l|}{ Phase 1} & \multicolumn{3}{|c|}{ Phase 2} & \multicolumn{3}{|c|}{ Phase 3} \\
\hline & & $\begin{array}{l}\text { Maximus } \\
\text { range } \\
(\mathrm{m})\end{array}$ & $\begin{array}{l}\text { Average value } \\
\text { of the range } \\
(\mathrm{m})\end{array}$ & $\begin{array}{l}\text { Minimum } \\
\text { range } \\
(\mathrm{m})\end{array}$ & $\begin{array}{l}\text { Maximus } \\
\text { range } \\
\text { (m) }\end{array}$ & $\begin{array}{l}\text { Average value } \\
\text { of the range } \\
\text { (m) }\end{array}$ & $\begin{array}{c}\text { Minimum } \\
\text { range } \\
\text { (m) }\end{array}$ & $\begin{array}{l}\text { Maximus } \\
\text { range } \\
\text { (m) }\end{array}$ & $\begin{array}{l}\text { Average value } \\
\text { of the range } \\
(\mathrm{m})\end{array}$ \\
\hline Span & 9 & 12 & 10.5 & 10 & 11 & 10.5 & 10 & 11 & 10.5 \\
\hline Height wall & 7 & 10 & 8.5 & 7 & 10 & 8.5 & 7 & 10 & 8.5 \\
\hline Height vault & 4 & 6 & 5 & 4.5 & 5.0 & 4.75 & 4.5 & 5.5 & 5.0 \\
\hline Thickness wall & 1 & 3.0 & 2 & 2.50 & 3.0 & 2.75 & 2.50 & 3.0 & 2.75 \\
\hline Thickness vault & 0.50 & 0.60 & 0.55 & 0.50 & 0.55 & 0.525 & 0.50 & 0.55 & 0.525 \\
\hline $\begin{array}{l}\text { Height to stone } \\
\text { key of vault }\end{array}$ & 12 & 14 & 13 & 12 & 14 & 13 & 12 & 15 & 13.5 \\
\hline
\end{tabular}




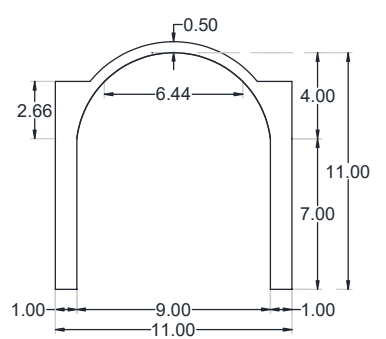

Phase 1. Minimum range Units. $\mathrm{m}$

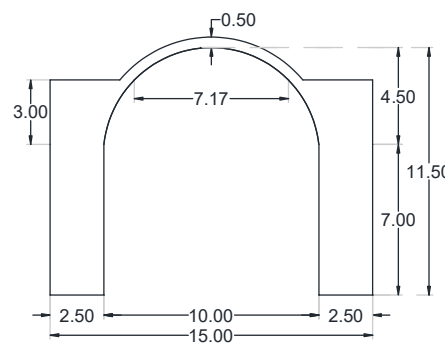

Phase 2. Minimum range Units. $\mathrm{m}$

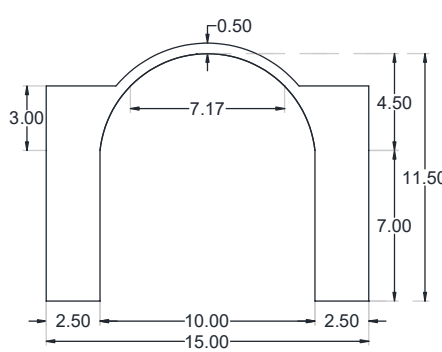

Phase 3. Minimum range Units. $\mathrm{m}$

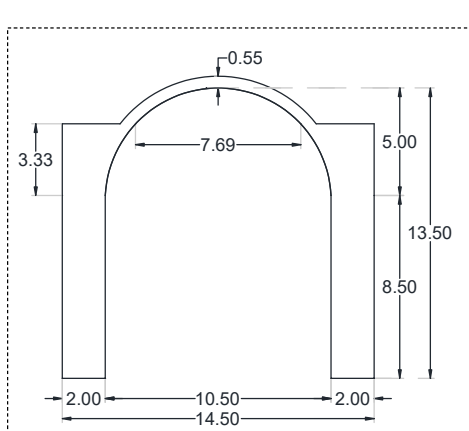

Phase 1. Average value of the range. Units. $\mathrm{m}$

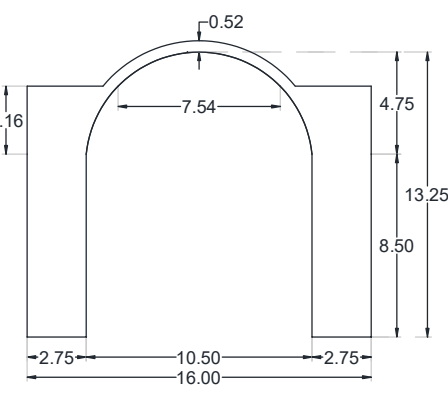

Phase 2. Average value of the range. Units. $\mathrm{m}$

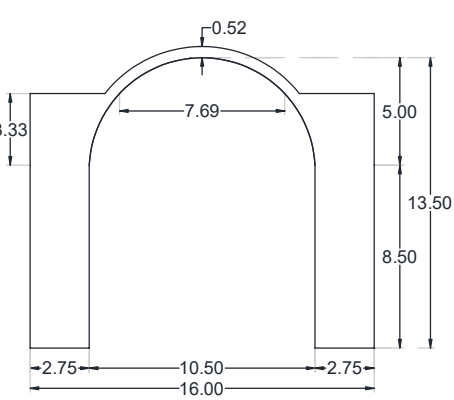

Phase 3. Average value of the range. Units. $\mathrm{m}$

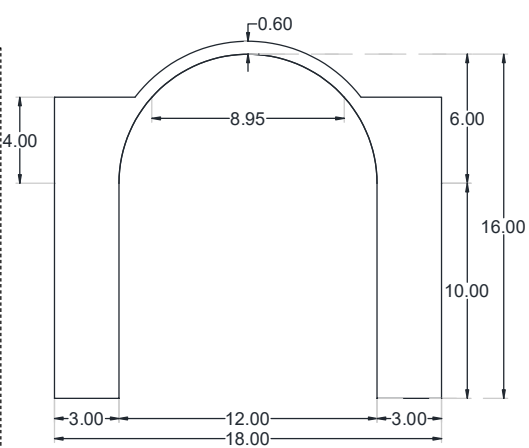

Phase 1. Maximums range Units. $\mathrm{m}$

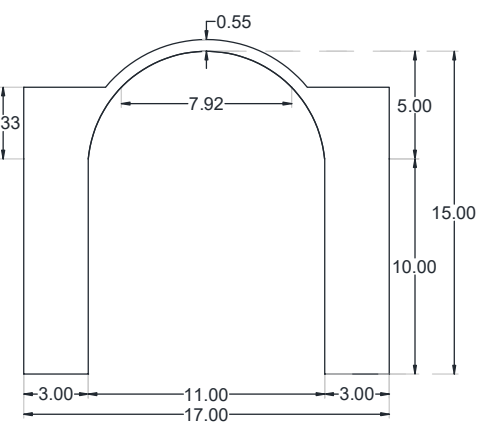

Phase 2. Maximums range Units. $\mathrm{m}$

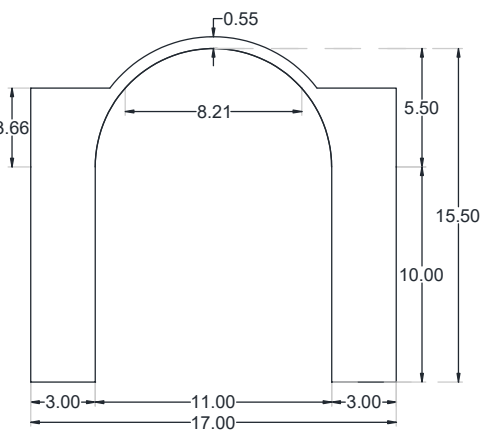

Phase 3. Maximums range Units. $\mathrm{m}$

Figure 8. Geometrical proposals in each stage (Image in proportion with dimensions).

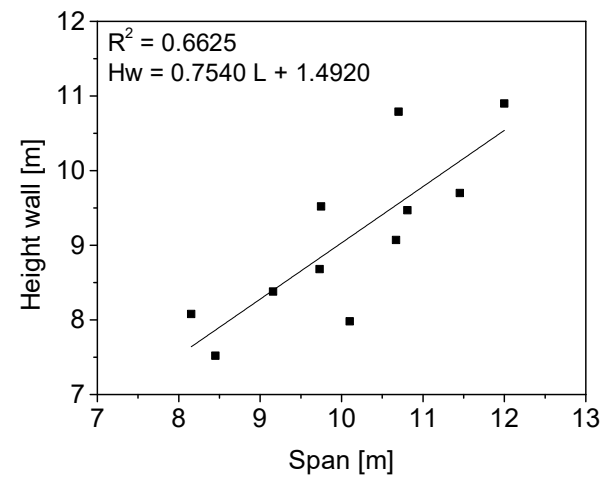

Figure 9. Churches with significant statistical correlation between Height wall and span

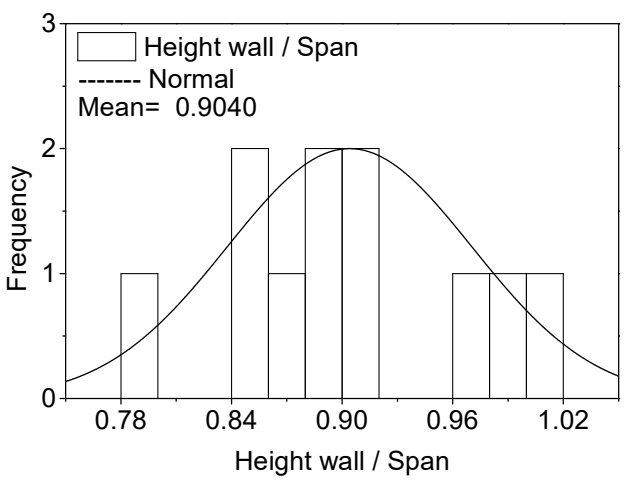

Figure 10. Histogram by the ratio Height wall/Span 
Equal to first approximation were selected the grater frequencies and average. The ranges selected are show in Table 4.

As a result, the linear correlation proposed between variables is show in Figure 11.

Table 3. Significant statistical correlation between variables

\begin{tabular}{lcc}
\hline \multicolumn{1}{c}{ Variables } & $\mathbf{R}^{\mathbf{2}}$ & Equation \\
\hline L vs Hw & 0.6625 & $\mathrm{Hw}=0.7540 \mathrm{~L}+1.4920$ \\
\hline L vs Hv & 0.9280 & $\mathrm{Hv}=0.5010 \mathrm{~L}-0.0477$ \\
\hline L vs tw & 0.6877 & $\mathrm{tw}=0.2359 \mathrm{~L}+0.4314$ \\
\hline L vs tv & 0.9301 & $\mathrm{tv}=0.0360 \mathrm{~L}+0.1045$ \\
\hline L vs Hk & 0.6268 & $\mathrm{Hk}=1.2907 \mathrm{~L}+0.6735$ \\
\hline
\end{tabular}

Table 4. Ranges of frequencies selected by geometrical rations.

\begin{tabular}{lccc}
\hline Frequencies & \multicolumn{3}{c}{ Second Campaign } \\
\cline { 1 - 3 } Relations & $\begin{array}{c}\text { range } \\
(\mathrm{m})\end{array}$ & $\begin{array}{c}\text { range } \\
\text { (m) }\end{array}$ & $\begin{array}{c}\text { value of the } \\
\text { range } \\
\text { (m) }\end{array}$ \\
\hline & & & \\
\hline $\mathrm{Hw} / \mathrm{L}$ & 0.84 & 0.92 & 0.90 \\
\hline $\mathrm{Hv} / \mathrm{L}$ & 0.495 & 0.505 & 0.50 \\
\hline $\mathrm{tw} / \mathrm{L}$ & 0.275 & 0.285 & 0.28 \\
\hline $\mathrm{tv} / \mathrm{L}$ & 0.043 & 0.047 & 0.045 \\
\hline $\mathrm{Hk} / \mathrm{L}$ & 1.25 & 1.55 & 1.40 \\
\hline
\end{tabular}

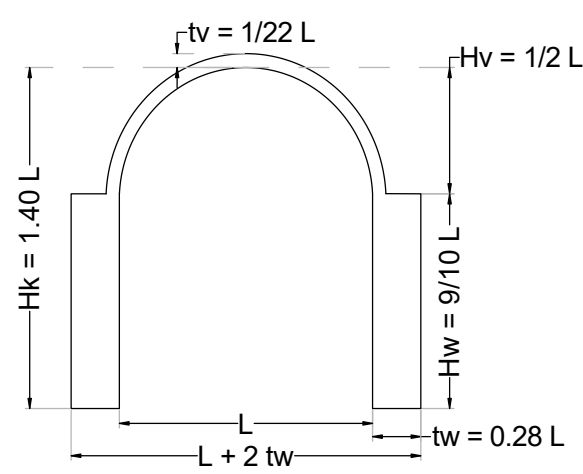

Figure 11. Geometrical rations between variables

\subsection{Extension wall}

The extension of walls over vaults is an important geometric characteristic, this leads to the reduction of the free span of the vault, as result it should have influence in the mechanical behaviour of the vaults.

The transversal sections of churches were analysed and statistical analysis were performed (e.g. Figure 12). The histograms shown that the walls height over the vault (Hext) ranges from $57 \%$ to $86 \%$ the total height of the vault $(\mathrm{Hv})$ and from $23 \%$ to $40 \%$ regarding the span of the vault (L). This leads to the reduction ( $R d$ ) of the free vault span ranging from $10 \%$ to $41 \%$ by span.

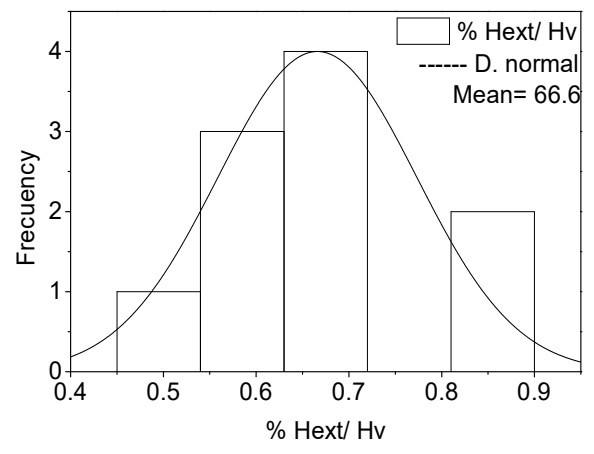

Figure 12. Reduction of the vault span

The Gaussian distribution reveals that the mean values by wall extension is $66.6 \%$ of height of vault and the $31.1 \%$ of span. These leads a reduction of the vault span about $26.1 \%$. In Figure 13 is show typical profile where the extension wall is the $66.6 \%$ of height of vault.

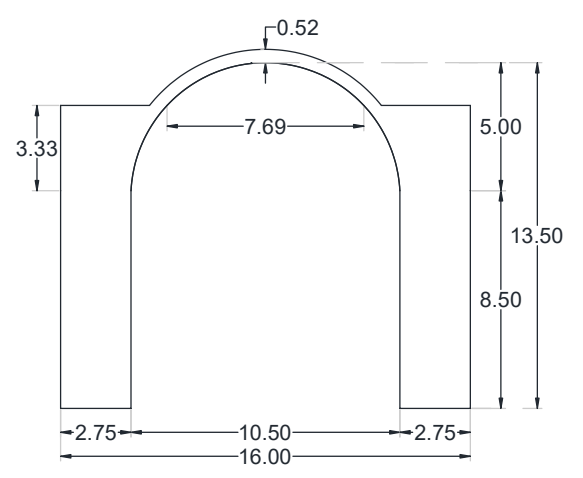

Figure 13. Geometry of first approximation Phase 3 (Average values) with extension wall of $0.666 \mathrm{Hv}$

\section{Analysis of results}

As a result, different geometrical proposed were obtained from each approximation. So, it was a conciliation between results.

From the first approximation were selected the average geometries proposed in each phase. See geometries inside the dotted boxing in Figure 8. 
The analysis of them show the identical span in the three geometries and equal to $10.5 \mathrm{~m}$. This span was evaluated with the Geometrical rations obtained in the second approximation. See Figure 14.

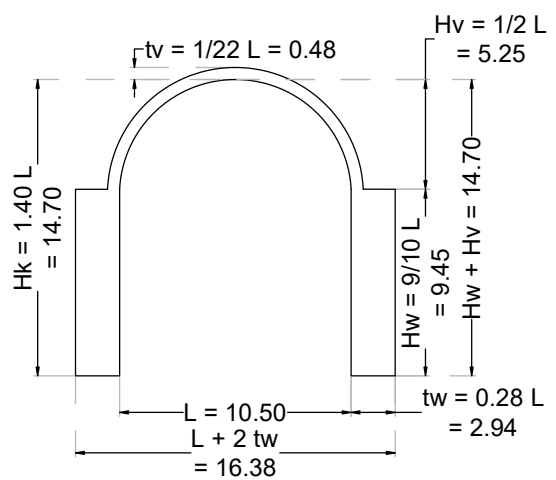

Figure 14. Span equal $10.50 \mathrm{~m}$ assessed with Geometrical rations proposed

Valuable to note that, with exception of the thickness of the vaults, the key dimensions obtained through Geometrical rations proposed are higher than the ones obtained through the one proposed from the statistical information.

In addition, a comparison between the geometrical rules described in manuscript or Spanish agreements[1]-[3] (Figure 3) and the Geometrical rations proposed was carried out (Figure 11). The aim was to determine if the Spanish rule used in prototypes of one nave church, could be used.

\section{Conclusions}

The main aim was determined the geometrical features of the typical profile that represent with the best accuracy the churches built in the south of Mexico. The comparation between both approximations and phases show that the differences between the geometries are not excessively dissimilar to those in the average geometry by Phase 3 from first approximation (Figure 8). So, this geometry was selected.

Regarding the extension wall is observable that there is a good approximation between the three relations proposed. Nevertheless, it is recommended a parametric analysis to determine the influence of the wall extension in the profile.
Additionally, linear correlation between variables is proposed as a function of the span, see the Figure 11, after the review of results those have a good approximation to barrel vaults structures.

It is important to note that, there are no rules that can define all churches of the database because the results do not show a clear numerical relationship. The geometrical relations defined are completely valid for two churches and partially valid for others fifteen churches. Regarding this, it is possible express that these churches could be built totally in an empirical or intuitive way.

In future works, the geometrical features of the typical profile proposed in this paper and linear correlations will allow to develop numerical simulations or experimental models with the purpose of understanding the structural behavior in the intervention projects.

\section{Acknowledgements}

The author would like to thanks to Sacred Art Commission of Yucatan, Yucatan State Government Restoration Department, Faculty of Architecture of the Autonomous University of Yucatan and the Specialized engineering services by Centeno Lara for their contributions regarding the geometrical information available in their private repositories.

\section{References}

[1] A. Brencich and R. Morbiducci, "Masonry arches: Historical rules and modern mechanics," Int. J. Archit. Herit., vol. 1, no. 2, pp. 165-189, 2007.

[2] S. Huerta, "Diseno estructural de arcos bovedas y cupulas en Espana ca. 1500 - ca. 1800," Universidad Politecnica de Madrid, MADRID, 1990.

[3] C. Perrault, Compendio de los diez libros de Arquitectura de Vitruvio, 2nd ed. Madrid: Imprenta de D. Gabriel Ramirez, 1761.

[4] N. García and Y. R. Meli, "Estudio de las bases estructurales de los templos conventuales mexicanos del siglo XVI," BOLETIN DE MONUMENTOS HISTORICOS, vol. 11, no. 01884638, pp. 4-18, 2007.

[5] D. de Landa, Relación de las cosas de Yucatán. Versión en línea. La Fundación El Libro Total. y (Sic) Editorial, 1566. 